\title{
Experimental studies of wind impact on coke chambers
}

\author{
Vladislav Pomelov ${ }^{*}$, Olga Poddaeva and Pavel Churin \\ Moscow State University of Civil Engineering, Yaroslavskoe shosse, 26, Moscow, 129337, Russia
}

\begin{abstract}
The article deals with the experimental investigation of the wind effect on coke chambers, which are part of delayed coking units. These structures are one of the most susceptible structures of an increased level of responsibility in the structure of industrial enterprises, which is primarily due to their height (height exceeds 100 meters). Experimental researches were carried out on the basis of the Educational Scientific and Production Laboratory for Aerodynamic Tests of Building Structures of NIU MGSU, using the Unique Scientific Installation of the Large Gradient Wind Tunnel. The text of the article shows the main features of the models made for carrying out experimental studies, briefly describes the process of testing and their results.
\end{abstract}

\section{Introduction}

The reliability and safety of building structures, their ability to withstand natural and manmade threats, largely depends on the correctness and accuracy of accounting for all types of loads at the design stage. One of the main types of effects to be taken into account is the wind force. Particular attention to the calculation of wind impact should be given in the design of buildings and structures that are part of hazardous industrial enterprises. Most of these structures are spatial permeable structures, such as external trestles, stacks with equipment [1]. One of the most dangerous types of permeable structures are coke chambers, whose height often exceeds 100 meters. The analytical calculation of the wind load on structures of this type, according to existing methods, gives only an estimate of the wind load (usually with a large margin) [2,3]. A more accurate numerical simulation of the wind effect for permeable structures is an extremely time-consuming process and requires high computational power and a considerable amount of time to perform the work, which does not allow us to speak of its effectiveness in this case $[4,5,6]$.

\footnotetext{
* Corresponding author: pomelov vladik@mail.ru
} 


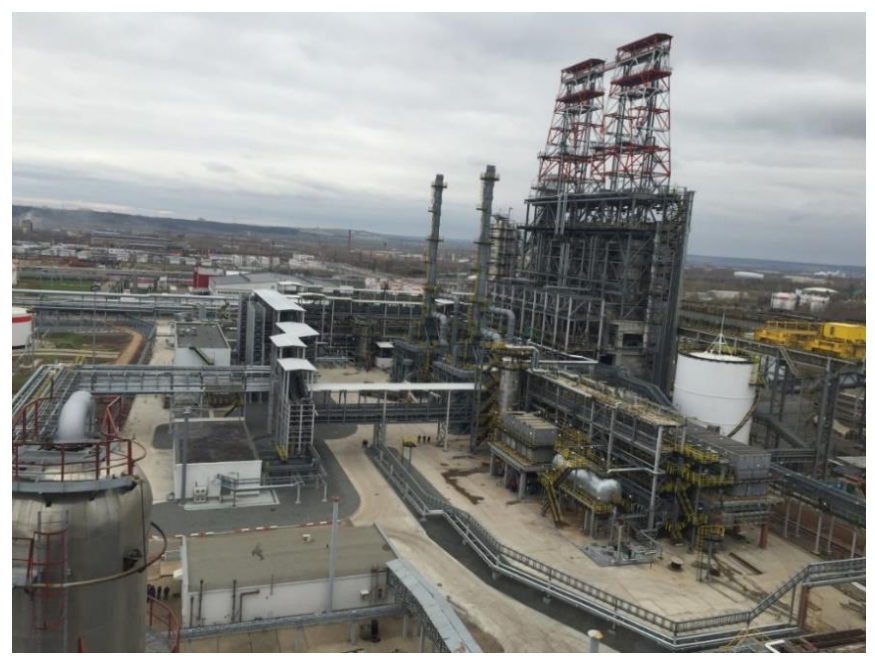

Fig. 1. Coking unit for delayed action

\section{Experimental study}

\subsection{Brief description of the research object}

Coke chamber is a reaction apparatus, which is the basis of the coking unit for delayed action, is technically arranged in the form of a cylindrical device equipped with a lower spherical bottom and an upper hemispherical one. The pedestal for its installation has a height of about twenty meters, it is equipped with metal structures equipped with equipment.
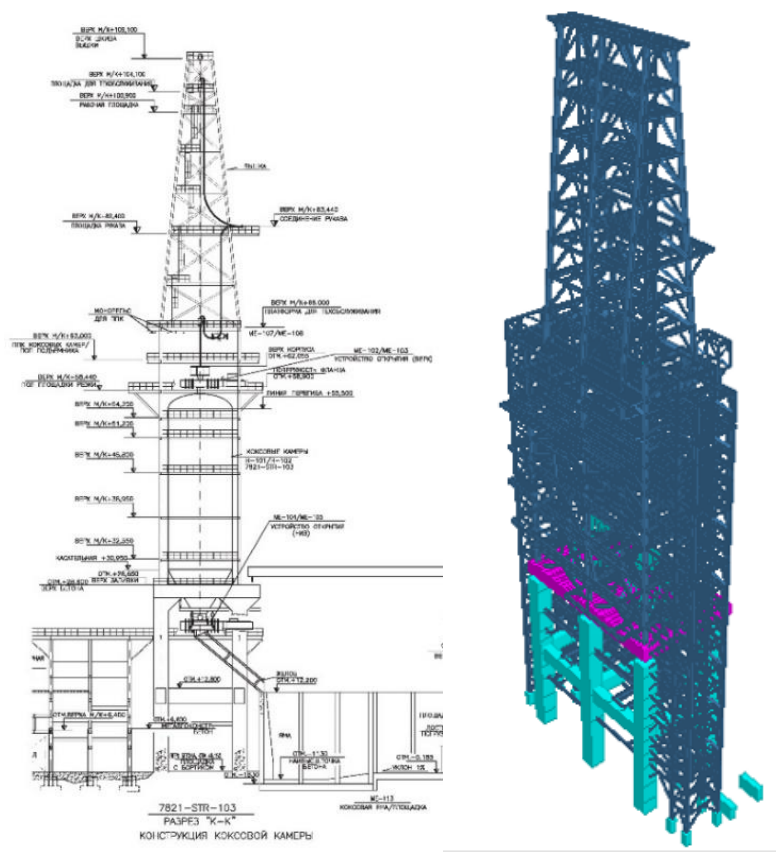

Fig. 2. Technical device of coke oven 


\subsection{Design and manufacture of a model for aerodynamic testing}

For the experimental studies, the most common designs of coke chambers were chosen in the territory of the Russian Federation, their models were developed and manufactured. Taking into account the dimensions of the working part of the wind tunnel, the maximum scale of the model of 1: 100 was chosen as far as possible from the cluttering conditions. The main requirement for a model for aerodynamic testing is the exact observance of geometric similarity to the object under study. The model is made of steel pins, metal and plexiglass $[6,7]$.

The investigated models were mounted on an automated rotary table, located in the working zone of the wind tunnel.

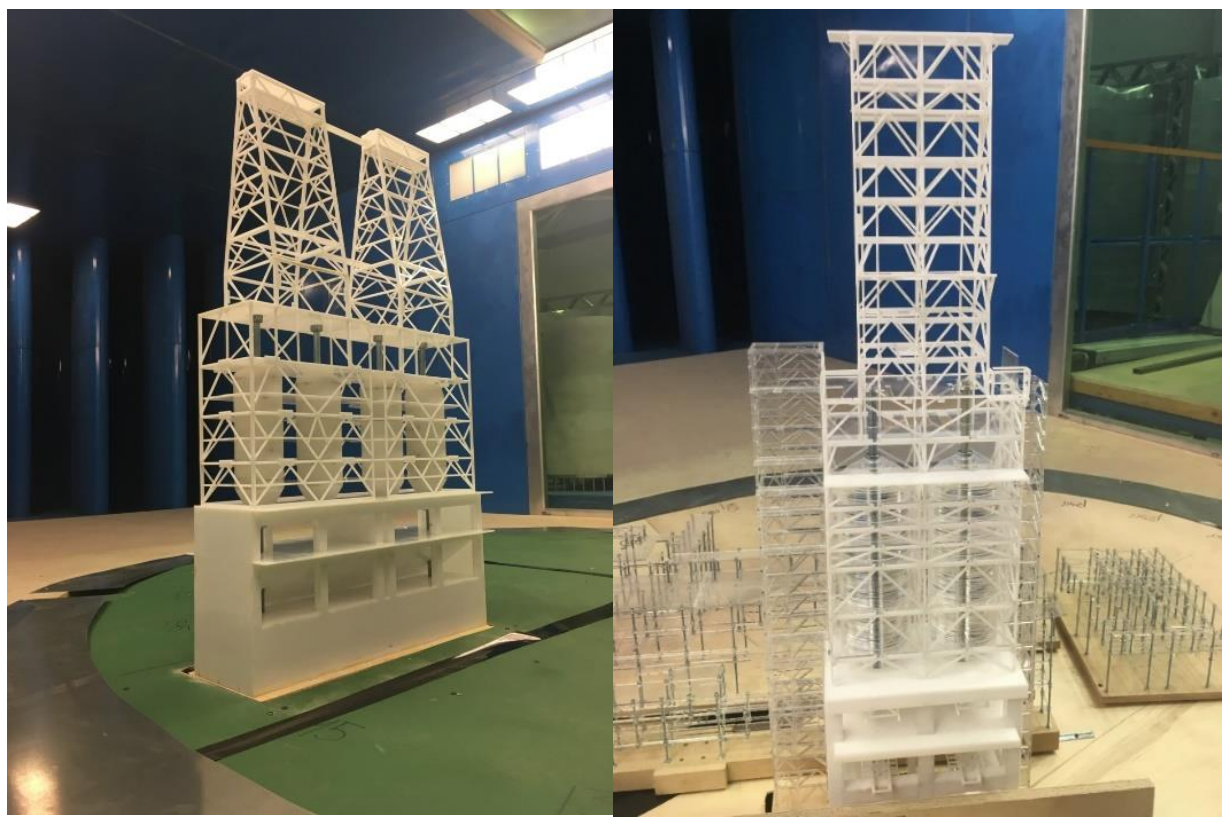

Fig. 3. Coke Chamber Models in the Wind Tunnel

At the stage of manufacturing the model, 6-component force-moment sensors, used to measure the resultant aerodynamic forces and moments, were built into the structures under investigation. The sensors are attached to a rigid metal plate at the base of the model. 


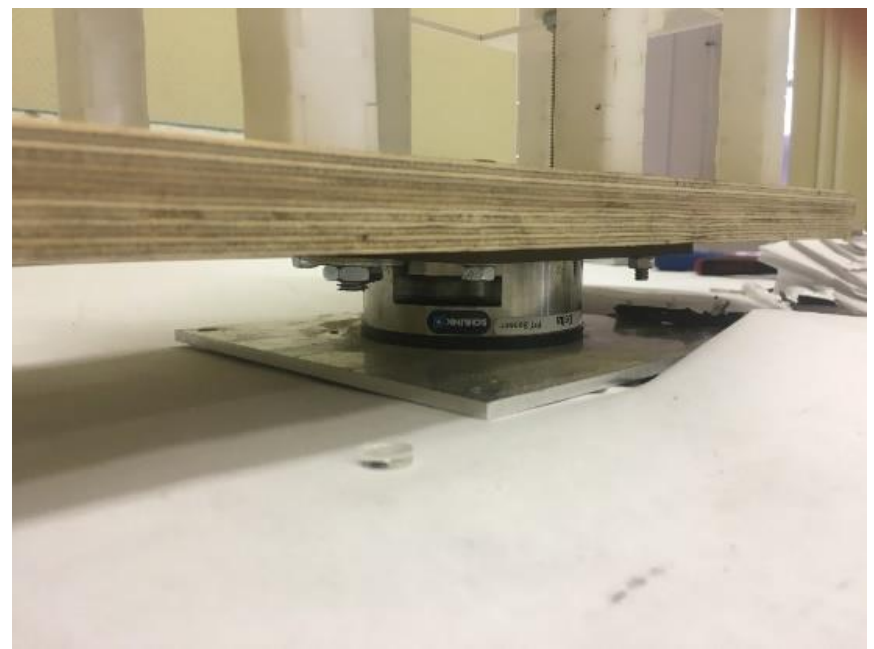

Fig. 4. 6-component force-torque sensor in the base of the model

\subsection{Determination of the values of aerodynamic coefficients}

Using six-component strain gages and software, Fx, Fy and $\mathrm{Mz}$ are the total forces and torques along the $\mathrm{X}, \mathrm{Y}$ and $\mathrm{Z}$ axes, respectively, and also $\mathrm{Cx}, \mathrm{Cy}$ and $\mathrm{CMz}$ are calculated, the total aerodynamic drag coefficients relative to the $\mathrm{X}, \mathrm{Y}$, and $\mathrm{Z}$ axes respectively.
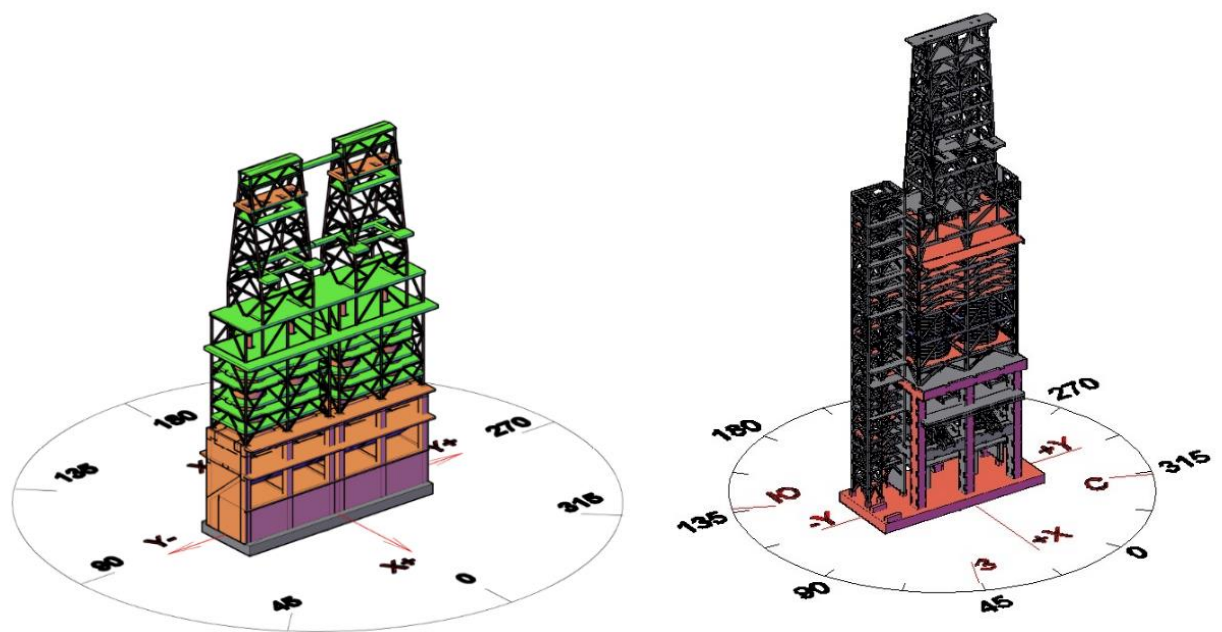

Fig. 5. Orientation of axes adopted during testing

\section{Test results}

Tables 1-2 give summaries of all the experimental data on the aerodynamic coefficients $\mathrm{Cx}$, $\mathrm{Cy}, \mathrm{Cmz}$ with the location of the sensor at the base of the model of the object under study with a change in the angle of attack $\beta$ from $0^{\circ}$ to $360^{\circ}$ in $45^{\circ}$ increments. In Fig. 8-9 are graphs of the dependence of aerodynamic coefficients on the angle of attack. 
Table 1. A summary of the experimental data on the aerodynamic coefficients $\mathrm{Cx}, \mathrm{Cy}, \mathrm{Cmz}$ with a change in the angle of attack from $0^{\circ}$ to $360^{\circ}$ - Coke chamber.

\begin{tabular}{|l|l|l|l|}
\hline \multicolumn{4}{|c|}{ Coke chamber } \\
\hline $\begin{array}{l}\text { attack } \\
\text { angle }\end{array}$ & $\mathrm{Cx}$ & $\mathrm{Cy}$ & $\mathrm{CMz}$ \\
\hline 0 & $-0,54$ & $-1,14$ & 0,0005 \\
\hline 45 & $-0,53$ & 0,63 & $-0,0154$ \\
\hline 90 & $-0,26$ & 1,79 & $-0,0081$ \\
\hline 135 & 0,11 & 1,27 & $-0,0021$ \\
\hline 180 & 0,61 & 0,76 & 0,0088 \\
\hline 225 & 0,63 & $-0,44$ & 0,0144 \\
\hline 270 & 0,29 & $-1,44$ & 0,0101 \\
\hline 315 & $-0,06$ & $-1,33$ & $-0,0013$ \\
\hline 360 & $-0,55$ & $-1,18$ & 0,0011 \\
\hline
\end{tabular}

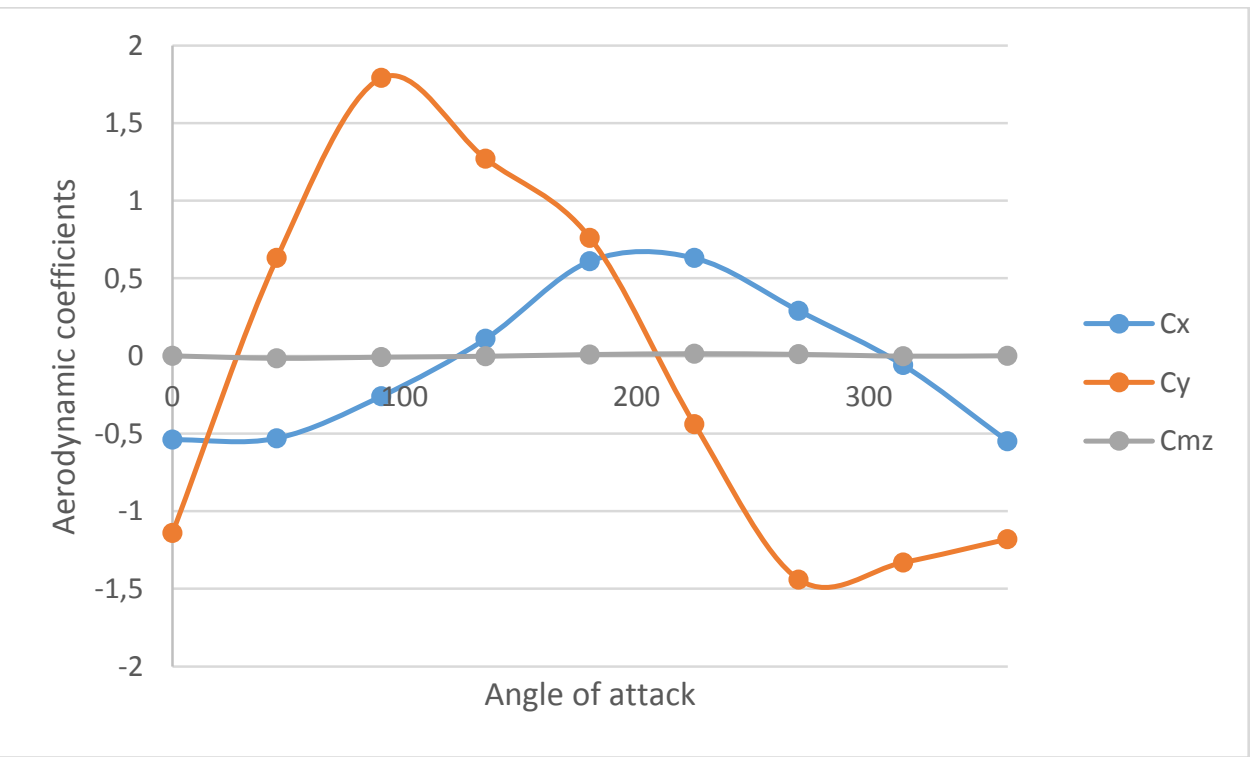

Fig. 6. The graph of the dependence of the aerodynamic coefficients $\mathrm{Cx}, \mathrm{Cy}, \mathrm{Cmz}$ with the angle of attack from $0^{\circ}$ to $360^{\circ}$ for the coking chamber 
Table 2. A summary of the experimental data on the aerodynamic coefficients $\mathrm{Cx}, \mathrm{Cy}, \mathrm{Cmz}$ with a change in the angle of attack from $0^{\circ}$ to $360^{\circ}$ - Block of coke chambers.

\begin{tabular}{|c|c|c|c|}
\hline \multicolumn{4}{|c|}{ Block of coke chambers } \\
\hline $\begin{array}{c}\text { attack } \\
\text { angle }\end{array}$ & $\mathrm{Cx}$ & $\mathrm{Cy}$ & $\mathrm{CMz}$ \\
\hline 0 & 0,93 & $-1,08$ & 0,0084 \\
\hline 45 & $-0,10$ & $-2,37$ & $-0,0145$ \\
\hline 90 & $-0,58$ & $-1,15$ & $-0,0355$ \\
\hline 135 & $-1,10$ & $-0,75$ & $-0,0657$ \\
\hline 180 & $-0,92$ & 0,78 & $-0,0166$ \\
\hline 225 & $-0,21$ & 1,95 & 0,1071 \\
\hline 270 & 0,56 & 1,16 & 0,0375 \\
\hline 315 & 1,30 & 0,48 & $-0,0185$ \\
\hline 360 & 0,91 & $-1,06$ & 0,0084 \\
\hline
\end{tabular}

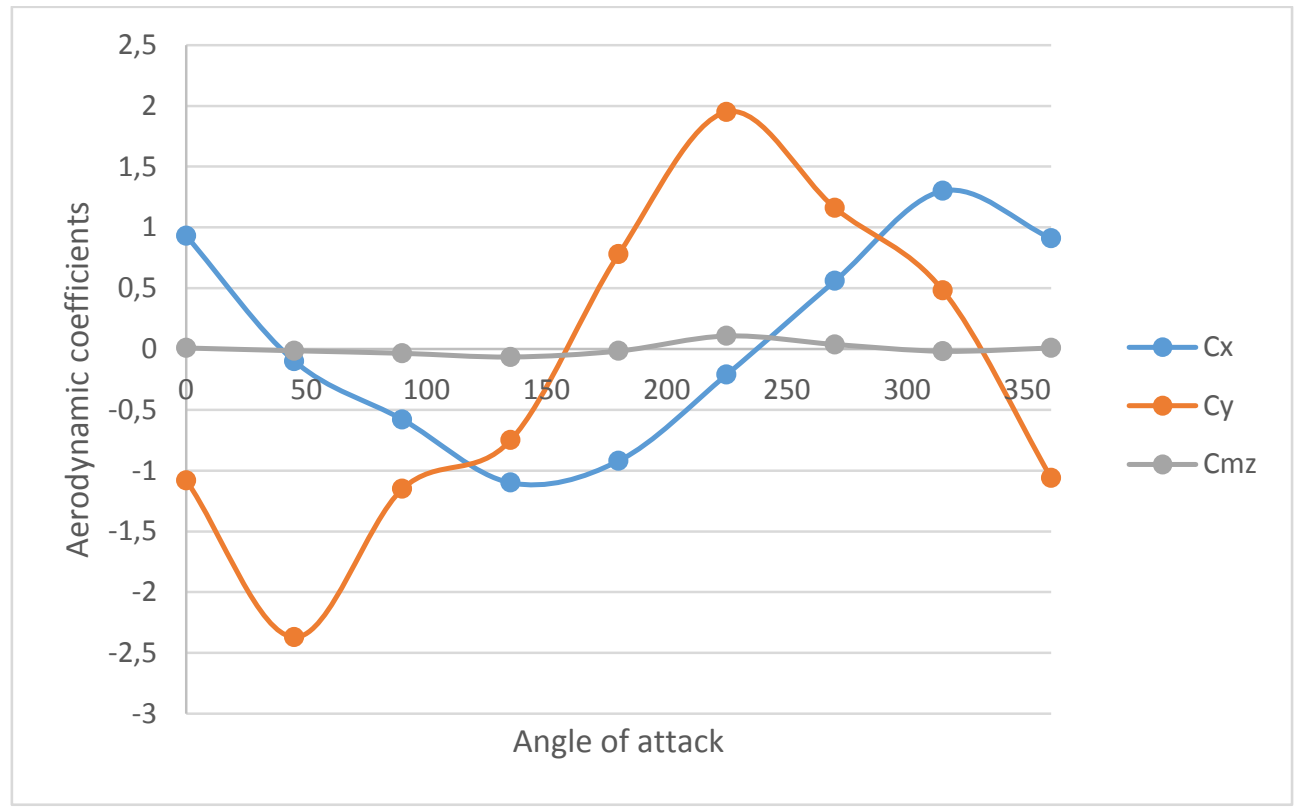

Fig. 7. The graph of the dependence of the aerodynamic coefficients $\mathrm{Cx}, \mathrm{Cy}, \mathrm{Cmz}$ with the angle of attack from $0^{\circ}$ to $360^{\circ}$ for the Block of coke chambers.

The maximum value of the load is realized with the largest area of interaction of the structure with the wind flow. In connection with the permeability of the objects under study, there is practically no torque around the vertical awn of the structure. 


\section{Conclusion}

Experimental studies of delayed-action coking plants indicate the need for further typification of hazardous industrial facilities and study of aerodynamics of this type of structures, since an incorrect assessment of the load on such buildings and structures, in addition to the threat of destruction of the object under study, can lead to an ecological catastrophe, The buildings and structures of the increased level of responsibility that are part of the enterprise th industry, on the basis of carrying out experimental research in wind tunnels, will increase the safe operation of facilities with an increased level of responsibility.

This work was financially supported by the Ministry of Education and Science (state task \#7.6075.2017/Bch). All tests were carried out using research equipment of The Head Regional Shared Research Facilities and Unique Scientific Installation Large Research Gradient Wind Tunnel of the Moscow State University of Civil Engineering.

\section{References}

1. P. Churin, V. Pomelov, O. Poddaeva, The research of wind loads on buildings and structures with increased level of responsibility (Procedia Engineering 153) pp 550 $555(2016)$

2. SP 20.13330.2011 Updated version of SNiP 2.01.07-85 Loads and impacts.

3. V. Pomelov, O. Poddaeva, P. Churin, A. Fedosova, FORM18, Analysis of domestic and foreign regulatory and scientific and technical documents in the field of wind influence on buildings and structures that are part of hazardous production facilities, (2018)

4. GOST R 56728-2015 Buildings and structures. Method for determining wind loads on enclosing structures

5. V.G. Gagarin, S.V. Gouvernyuk, A.S. Kubenin, A.A. Sinyavin, Vestnik Otdeleniya stroitel'nykh nauk Rossiyskoy akademii arkhitektury i stroitel'nykh nauk. T.18 (pp 151156), Questions of application of modern computer technologies for solving practical problems of building aerodynamics (2014)

6. Cermak J. E. Wind-tunnel development and trends in applications to civil engineering. Journal of wind engineering and industrial aerodynamics, 2003, vol. 91, no. 3, pp. 355370.

7. Niu, J. Q., Zhou, D., Liang, X. F., Liu, S., \& Liu, T. H., Journal of Wind Engineering and Industrial Aerodynamics 173, 187-198, Numerical simulation of the Reynolds number effect on the aerodynamic pressure in tunnels (2018) 